\title{
Height Extraction and Stand Volume Estimation Based on Fusion Airborne LiDAR Data and Terrestrial Measurements for a Norway Spruce [Picea abies (L.) Karst.] Test Site in Romania
}

\author{
Bogdan APOSTOL ${ }^{1,2 *}$, Adrian LORENT, ${ }^{1,2}$, Marius PETRILA ${ }^{1}$, \\ Vladimir GANCZ ${ }^{1}$, Ovidiu BADEA ${ }^{1,2}$ \\ ${ }^{I}$ National Institutefor Research and Development in Forestry (INCDS) "Marin Drăcea", 128 B-dulEroilor, Voluntari, Ilfor, \\ Romania;bogdanap_ro@yahoo.com("correspondingauthor);lorentadrian@yahoo.co.uk;mariuspetrila@yahoo.com;vlgancz@yahoo.com; badea63@yahoo.com \\ ${ }^{2}$ Transilvania University of Brasov, Faculty of Silvicultureand Forest Engineering, 1 Sirul Beethoven Street 500123 Brasov, Romania
}

\begin{abstract}
The objective of this study was to analyze the efficiency of individual tree identification and stand volume estimation from LiDAR data. The study was located in Norway spruce [Picea abies (L.) Karst.] stands in southwestern Romania and linked airborne laser scanning (ALS) with terrestrial measurements through empirical modelling. The proposed method uses the Canopy Maxima algorithm for individual tree detection together with biometric field measurements and individual trees positioning. Field data was collected using Field-Map real-time GIS-laser equipment, a high-accuracy GNSS receiver and a Vertex IV ultrasound inclinometer. ALS data were collected using a Riegl LMS-Q560 instrument and processed using LP360 and Fusion software to extract digital terrain, surface and canopy height models. For the estimation of tree heights, number of trees and tree crown widths from the ALS data, the Canopy Maxima algorithm was used together with local regression equations relating field-measured tree heights and crown widths at each plot. When compared to LiDAR detected trees, about $40-61 \%$ of the field-measured trees were correctly identified. Such trees represented, in general, predominant, dominant and co-dominant trees from the upper canopy. However, it should be noted that the volume of the correctly identified trees represented $60-78 \%$ of the total plot volume. The estimation of stand volume using the LiDAR data was achieved by empirical modelling, taking into account the individual tree heights (as identified from the ALS data) and the corresponding ground reference stem volume. The root mean square error (RMSE) between the individual tree heights measured in the field and the corresponding heights identified in the ALS data was 1.7-2.2 meters. Comparing the ground reference estimated stem volume (at trees level) with the corresponding ALS estimated tree stem volume, an RMSE of 0.5-0.7 $\mathrm{m}^{3}$ was achieved. The RMSE was slightly lower when comparing the ground reference stem volume at plot level with the ALS-estimated one, taking into account both the identified and unidentified trees in the LiDAR data $\left(0.4-0.6 \mathrm{~m}^{3}\right)$.
\end{abstract}

Keywords: airborne LiDAR data, data fusion, Field Map, ground reference measurements, tree height, volume estimation

\section{Introduction}

The use of airborne LiDAR technology (a term first used by Middleton and Spilhaus, 1953), as a part of modern active sensor remote sensing, has grown rapidly and continuously, boosted by the necessity of obtaining more precise geospatial information about topography, such as digital terrain model (DTM) and digital surface model (DSM) (Popescu et al., 2002; Dorren et al., 2006; Maguya et al., 2014). LiDAR systems may operate on the ground, in the air or from satellite platforms.

In forestry, LiDAR data are used to monitor changes in forest vegetation and forest inventory, to assess the risks of disasters caused by wind or fire and to map forest ecosystems and habitats (Hyde et al., 2005; Skowronski and Lister, 2012;
Montealegre et al., 2014). The so far studies undertaken demonstrate the potential of LiDAR technology for both coniferous and deciduous forests (Popescu et al., 2003; Reitberger et al.,2008; Tan and Haider, 2010; Parent and Volin, 2014).

Forest stand parameters can be estimated from LiDAR data using one of two major approaches: an area-based approach (using stand mean height and density) or a single tree-based approach (detecting and measuring individual trees). If the objective is to predict forest attributes at plot and stand level in large areas, the area-based approach using low pulse density $\operatorname{LiDAR}\left(<1\right.$ pulse $\left.\mathrm{m}^{-2}\right)$ and small plots offers good results. Ruiz et al. (2014) assessed the combined effect of field plot size and LiDAR density on the estimation of four forest structure attributes - volume, total biomass, basal area and canopy cover showing that the plot size has a greater effect on the estimation error than the LiDAR point density. If more detailed 
314

information regarding structure is needed, individual tree-based estimation is appropriate. Such methods require a higher LiDAR pulse density $\left(6-8\right.$ pulses $\left.\mathrm{m}^{-2}\right)$ to provide a sufficient number of treetop hits, as well as more detailed information from larger field plots (Popescu and Wynne, 2004). However, the fieldwork required for establishing large plots is expensive, while changing LiDAR flight parameters (reduced flight speed, lower flight altitude, multiple passes) to achieve the required point densities becomes a limiting factor over large areas due to time and/or costs constraints. Overall, the point densities needed for individual tree detection and measurements are in the range of 10 points $\mathrm{m}^{-2}$, with higher point densities only marginally improving the performance of 3D tree detection (Yao et al., 2014).

By using LiDAR data, it was possible to estimate tree heights at stand level (Magnussen and Boudewyn, 1998) as well as individual tree stem volumes (Nasset, 1997; Lim et al., 2003). More recently, some studies have demonstrated the possibility of differentiating between tree species (Holmgren and Persson, 2004; Vaughn et al., 2012) or delineating forest stands (Eysn et al., 2012; Sačkov and Kardoš, 2014). In addition, algorithms for automatic identification of the individual trees (tree detection) have been continuously improving, using $2 \mathrm{D}$ or $3 \mathrm{D}$ segmentation of LiDAR data or a combination of LiDAR data and aerial or satellite imagery. Eysn $e t$ al. (2015) found that forest structure has a significant influence on the tree identification results, with the highest matching rate (86\% RMS) for single-layered coniferous and the lowest matching rate (47\% RMS) for single-layered mixed forests. Various studies have demonstrated the utility of LiDAR technology for the estimation of height, stand basal area, total tree biomass or foliage biomass mainly in coniferous stands (Hall et al., 2005; Lefsky et al., 2005; García et al., 2010; Edson and Wing, 2011). Goodwin et al. (2006) tested different flight altitudes, scan angles and footprint sizes to assess the structure of eucalypt stands. They observed that the platform altitude and footprint size do not have a major influence on canopy height profiles derived from LiDAR data.

The forest studies concerning the use of LiDAR data are focused on the identification of biometric parameters such as the tree height and crown size at the stand level, on sample plots or individual tree level. Then, either biometric relations or statistical analyses are used to estimate other characteristics, such as biomass, volume, crown density or crown base height (Popescu and Zhao, 2008). Estimating biomass using airborne LiDAR data is increasingly preoccupying several researchers, the correlation between the volume and biomass of trees has been well proven (Popescu, 2007; Zhao et al., 2009; Petrila et al., 2012a; Tao et al., 2014).

Research regarding the estimation of forest biomass using airborne LiDAR technology both within and outside the growing season, confirms a strong statistical relationship between LiDAR variables and biomass (Anderson and Bolstad, 2013, Hansen et al., 2014; Hernández-Stefanoni et al., 2015). Shendryk et al. (2014) combined SPOT 5 multispectral images with airborne LiDAR data to identify treetops in coniferous forests in southwestern Sweden by applying Fusion, TreeVaW and watershed segmentation algorithms (methods) to identify treetops. Such methods could be extended to other geographical areas or different multispectral imagery and low-density LiDAR data. Recently, LiDAR data were used to estimate the impact of forest fires (Montealegre et al., 2014) and to characterize and spatially quantify the vertical structure of canopy ladder forest fuels across large areas (Kramer et al., 2014), demonstrating the increasing importance of airborne LiDAR for a range of forestry applications.

Promising results were achieved when combining LiDARbased information with multispectral images to identify trees in deciduous forests (Popescu and Wynne, 2004; Popescu et al., 2004). Using statistical methods and airborne LiDAR data, satisfactory results were obtained when estimating the biometric characteristics of individual trees from mixed beech and spruce stands (Heurich and Thoma, 2008).

More recently, a new segmentation method based on a graph segmentation algorithm was proposed in order to identify individual tree crowns using LiDAR data (Strîmbu and Strîmbu, 2015).

Earlier studies in Romania have proved that 3D information from LiDAR data can be used to obtain accurate estimates of tree heights and, consequently, the volume and biomass for spruce stands, as well as to extract high-precision digital terrain models (Apostol et al., 2011, 2012; Petrila et al. 2012a, b).

The main objective of this study was to analyze the possibility offered by LiDAR data to identify individual trees and estimate their volume (stem and stand level) in Romanian spruce forests, for which far less studies are currently available. A second objective was to investigate the possibility of obtaining height estimates (and thus stem volumes) for the remaining unidentified trees.

\section{Materials and Methods}

\section{Study area}

The study was located in Voineasa Forest District, in the southwestern part of Romania. The forests of Voineasa Forest District are located between 650 and 1850 meters altitude and the predominant species are Norway spruce (Picea abies L.), silver fir (Abies alba Mill.) and beech (Fagussylvatica L.).

Three pure Norway spruce stands of different ages within Management Unit IV - Puru and Management Unit V Obârşia Lotrului were chosen as field reference measurements plots (Fig. 1). The first pure plot of Norway spruce is located in stand 118D, Management Unit V Obârşia Lotrului. The forest management plan describes the stand as a 110 years old stand with a site index class of three and medium (0.8) canopy cover. (Romanian classification of site index class is based on a methodology that considers the medium heights and the ages of the stands, and was used for the first time when the first Romanian yield tables were developed, 1951-1955, PopescuZeletin, 1957). The canopy cover is defined as the proportion of the forest floor covered by the vertical projection of the tree crowns (Jennings et al., 1999) and takes a value between 0.1 (least cover) and 1 (complete cover). The second plot is located in stand 43C, Management Unit IV - Puru. The forest management plan describes this stand as a 65 years old stand with a site index class of three and medium (0.9) canopy cover. The third pure spruce plot is located in stand 62A, Management Unit IV - Puru. The forest management plan describes it as a 90 years old stand with a site index class of three and medium (0.8) canopy cover.

\section{Groundreference data}

In each of the three stands (118D, 43C and 62A), square plots $(100 \times 100 \mathrm{~m})$ were placed using Field Map equipment 


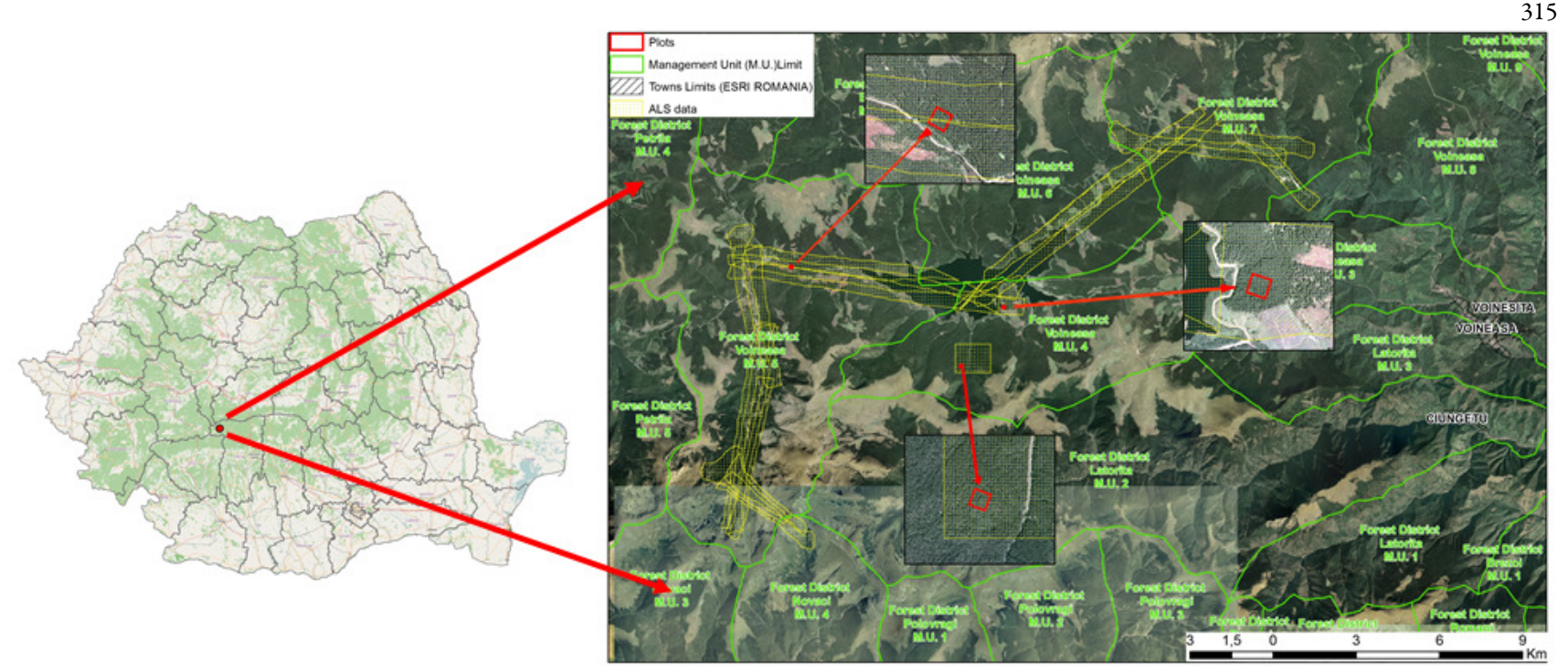

Fig. 1. Location of the test site. A) General view (map source: OpenStreetMap); B) Detailed view of the plots location overlaid with ortorectified aerial images acquired in 2003-2005 by Romanian National Agency for Cadastre and Land Registration (0.5m spatial resolution)

and Field Map Data Collector software (IFER 1999-2006; Vopěnka and Cerný, 2006) (specialized equipment and software used in forest inventories). The plots were placed and measured in three different periods: October 2011 (plot 118D), April 2012 (43C) and August 2013 (62A). The position of trees, the crown projections, the vertical profile of the crowns class were measured in a local coordinate system Using Field Map and descriptive data such as Kraft class was visually determined in the field. The classification introduced by Kraft (1884) assesses the vitality and competitive intensity of the trees based on five social classes: predominant (class I), dominant (class II), co-dominant (class III), dominated (class IV) and suppressed (class V). Tree heights were measured using a Vertex IV ultrasound device and tree diameters with an electronic caliper and then both measurements were imported into the Field Data Collector software. The height measuring errors are comparable for Vertex IV and the Field Map laser rangefinder (e.g. $0.1 \mathrm{~m}$ ). However, the procedure of measuring tree height is significantly slower using the rangefinder since it necessitates moving around while carrying all of the Field-Map equipment, which is relatively heavy. In addition, many operations are necessary for positioning the device. In comparison, Vertex IV offers greater mobility and efficiency as it is very light and quick to position. The time required for tree height measurements is thus significantly reduced (at least by half) by using the Vertex IV.

The position of one corner of each plot was measured using a Trimble Geo XH receiver with a Zephir II external antenna. The corner coordinates were used to convert the local coordinate system of the field measurements to the same coordinate system in which the LiDAR data were provided, Universal Transverse Mercator (UTM) 34 North zone.

\section{Airborne laser data}

The airborne LiDAR data were collected in 2008 and 2012, respectively, using a Diamond Aircraft Industries plane (the DA42 MPP). For data acquisition, the plane was equipped with a full-wave Riegl LMS-Q560 laser scanner, which collects realtime corrected echo signals using global positioning system (GPS) and inertial measurement unit of the plane. To reach the laser point density of 4 points $\mathrm{m}^{-2}$, the same area of forest was covered two or three times by the laser scanner. The projection of the raw LiDAR data was Universal Transverse Mercator (UTM) for 34 North zone. The flight parameters and the specifications of the LiDAR scanner are presented in Table 1. For both time periods (2008 and 2012), the data were delivered with the matched scan lines but unclassified. LiDAR data collected from 2008 cover plots $118 \mathrm{D}$ and $43 \mathrm{C}$, and the LiDAR data collected in 2012 cover plot 62A.

\section{Methodology}

In order to achieve the best possible accuracy for the ground reference data, the corner position of each plot recorded by the Geo XH receiver was differentially post-processed using the closest EUREF (European reference frame) station, in this case DEVA, located approximately $90 \mathrm{~km}$ from the ground reference plots. The final positioning accuracy was between 0.6 and $1.7 \mathrm{~m}$ depending on the plot.

The raw LiDAR data were clipped by each square plot separately, linking thus the LiDAR data to the terrestrial measurements within plots. The LiDAR points (the last return echoes) were partially classified into ground class using an automatic ground classification algorithm based on the Adaptive TIN Ground Filter method of the LP360 software (QCoherent Software LLC, Madison, AL, USA; Weir, 2012). Because the area of interest was mostly covered with vegetation, the rest of the LiDAR points were reclassified as vegetation class. Based on the ground class, the digital terrain model (DTM) was generated separately for each plot. The extraction of the normalized canopy height model (CHM) for each plot was made using all LiDAR points excepting those classified as "ground". Both the DTM and CHM were extracted with a spatial resolution of 0.5 meters using a median $3 \times 3$ filter. 
Each normalized CHM was imported into Fusion software (McGaughey, 2014) and it was followed by the automatic identification of trees using the Canopy Maxima (Popescu et al., 2002; Popescu and Wynne, 2004) algorithm. This algorithm identifies the local maxima with some limitations based on the correlation between crown width and tree heights (Popescu et al. 2002; Popescu and Wynne 2004). To achieve better results for this method, the correlation and regression equations between the two parameters should be customized as much as possible per tree species, ages and site index classes. This aim could be achieved at a national level, taking advantage of the results from the national forest inventories. In our case, we did not have this type of standardized equations for each species, so we had to instead build our local equations based on crown diameter and tree height measurements for each plot. Since we measured the crown projection area $\left(\mathrm{Pr}_{\text {crown }}\right)$ in the field, the crown diameter $\left(\mathrm{d}_{\text {crown }}\right)$ was calculated based on a circular shape of the crown projection area (eq. 1):

$$
d_{\text {crown }}=\sqrt{\frac{4 \mathrm{Pr}_{\text {crown }}}{\pi}}
$$

The Canopy Maxima specific parameters computed locally for each plot are presented in Table 2. The algorithm output is a .csv file containing the coordinates, height and crown width of each individual identified tree. The positions of ground reference-measured trees were imported into the Fusion software, and then linked visually with the Canopy Maxima identified trees (i.e. according to nearest neighbour).

In order to calculate the deviations of the LiDAR-estimated tree heights $\left(h_{\text {LDAAR }}\right)$ from the corresponding linked tree heights as measured in the field, the root mean square error $\left(R M S E_{h}\right)$ was determined for each plot (eq. 2):

$$
R M S E_{h}=\sqrt{\frac{\sum_{1}^{n}\left(h_{\text {Fitd }}-h_{L D D A R}\right)^{2}}{n}}
$$

The ground reference tree stem volume $\left(\mathrm{v}_{\mathrm{i}}\right)$ of each tree was calculated using a double logarithmic equation with tree diameter at the breast height $(\mathrm{DbH})$ and height $(\mathrm{h})$ as variables (eq. 3) (Giurgiu et al., 2004):

$\log v_{i}=b_{0}+b_{1} * \log D b H+b_{2} * \log ^{2} D b H+b_{3} * \log h+b_{4} * \log ^{2} h$

The total volume (per hectare) was calculated by summing the stem volumes of all individual trees.

The estimation of stem volumes for the identified LiDAR trees corresponding with ground measured trees was determined through empirical modelling of ground reference stem volume $\left(V_{i}\right)$ and LiDAR height $\left(h_{i, L D A R}\right)$ for each linked tree, regression coefficients being determined for each plot separately (eq. 4):

$$
V_{i}=b_{0} * e^{b_{1}{ }^{*} h_{i, L D A R}}
$$

The ground reference tree stem volumes and the corresponding LiDAR estimated tree stem volumes do not follow a normal distribution. Therefore, we used the Wilcoxon test in order to test the significance of the difference between the mean volume for the population of the identified LiDAR trees and the mean volume for the population of the corresponding reference field trees (for the same number of trees).

\begin{tabular}{|c|c|}
\hline \multicolumn{2}{|c|}{ LiDAR scanner parameters } \\
\hline Pulse Repetition Rate $[\mathrm{Hz}]$ & 100,000 \\
\hline Field of view [degrees] & 60 \\
\hline Scan rate $\left[\right.$ lines sec $\left.{ }^{-1}\right]$ & 58.9 \\
\hline \multicolumn{2}{|c|}{ Flight parameters } \\
\hline Flight altitude $[\mathrm{m}]$ & 750.0 \\
\hline Groundspeed $\left[\mathrm{ms}^{-1}\right]$ & 54.0 \\
\hline \multicolumn{2}{|c|}{ Scan pattern } \\
\hline Scan Line Spacing [m] & 0.9168 \\
\hline Point Spacing In Line [m] & 0.6938 \\
\hline Point density $\left[1 \mathrm{~m}^{2}\right]$ & 1.6 \\
\hline Stripe width $[\mathrm{m}]$ & 866.0254 \\
\hline Maximum point distance $[\mathrm{m}]$ & 0.925 \\
\hline
\end{tabular}

Table 1. Technical details of the flight parameters and LiDAR scanner parameters

Table 2. Canopy maxima specific parameters (A,B,C,D) computed locally for each plot

\begin{tabular}{ccccc}
\hline \multirow{2}{*}{ Plot } & \multicolumn{4}{c}{ Canopy maxima specific parameters } \\
\cline { 2 - 5 } & $\mathrm{A}$ & $\mathrm{B}$ & $\mathrm{C}$ & $\mathrm{D}$ \\
\hline $118 \mathrm{D}$ & 3.05 & -0.0576 & 0.0027 & 0 \\
43C & 2.9999 & -0.0919 & 0.0035 & 0 \\
$62 \mathrm{~A}$ & 2.7651 & -0.0411 & 0.0026 & 0 \\
\hline
\end{tabular}

To measure the deviations of the LiDAR estimated stem volume of each tree $\left(v_{L I D A R}\right)$ and the corresponding ground reference stem volume $\left(v_{\text {Field }}\right)$, the root mean square error $\left(R M S E_{V}\right)$ was calculated for each plot (eq. 5):

$$
R M S E_{V}=\sqrt{\frac{\sum_{1}^{n}\left(v_{\text {Filld }}-v_{\text {LiDAR }}\right)^{2}}{n}}
$$

For the purpose of validating the empirical model, the LiDAR-identified trees were split randomly into two equal samples; each sample was used successively to calibrate the model using eq. 4 , while the other sample was used for validation purposes using eq. 5. We considered the best-fitted model the one that had the highest coefficient of determination $\left(\mathrm{R}^{2}\right)$ for each plot, and used this for the further volume calculation.

In addition, eq. 4 was calibrated using the data from all the plots and used afterwards to compute the RMSE (eq. 5) for each plot separately.

To estimate the stem volume of the unidentified LiDAR trees (the real trees that were not detected by the Canopy Maxima algorithm), we used eq. 4 and the unidentified LiDAR tree heights. These heights were estimated using the equation computed between the tree diameter at breast height $(\mathrm{DbH})$ measured in the field and the corresponding automatic tree height identified by LiDAR data $\left(h_{\text {LiDAR }}\right)$ (eq. 6). The regression coefficients were calculated for each plot using a specific methodology (Giurgiu et al. 2004):

$$
\ln h_{\text {LDAR }}=a_{0}+a_{1} * D b H^{a_{2}}
$$

The assessment of the estimation errors per plot at stand level between the field reference volume and LiDAR derived volume was performed using the cumulated single stems estimated volumes of both identified and unidentified trees.

The root mean square error $\left(R M S E_{v_{-}}\right)$was computed again for each plot, taking into account the estimated tree stem volume of both identified and unidentified LiDAR trees and the field 
Table 3. Total stand volume calculated for the field measurement and the descriptive statistics for each plot

\begin{tabular}{ccccccc}
\hline Plot & $\begin{array}{c}\text { Area } \\
\text { of the } \\
\text { plot } \\
(\mathrm{ha})\end{array}$ & $\begin{array}{c}\text { Total number } \\
\text { of reference } \\
\text { field trees } \\
(\mathrm{N})\end{array}$ & $\begin{array}{c}\bar{d} \\
(\mathrm{~cm})\end{array}$ & $\begin{array}{c}\bar{h} \\
(\mathrm{~m})\end{array}$ & $\begin{array}{c}\bar{v} \\
\left(\mathrm{~m}^{3}\right)\end{array}$ & $\begin{array}{c}\text { Volume } \\
\left(\mathrm{m}^{3}\right)\end{array}$ \\
\hline 118D & 1 & 414 & 38.9 & 30.5 & 1.9 & 792.9 \\
\hline 43C & 1 & 820 & 29.4 & 28.9 & 1.1 & 875.9 \\
\hline $62 \mathrm{~A}$ & 1 & 748 & 32.0 & 27.1 & 1.2 & 880.5 \\
\hline
\end{tabular}

Table 4. The mean tree heights $\left(\bar{h}_{\text {Field }}\right)$ based on the field measured trees and the mean tree heights identified on LiDAR data $\left({\left(\bar{h}_{L D A R}\right.}_{{ }_{L A}}\right)$ determined for the same trees with the errors of LiDAR heights estimations presented by their deviations from the field measurements $\left(\Delta_{\mathrm{h}}\right)$ and the root mean square error $\left({ }_{R M S E_{h}}\right)$

\begin{tabular}{cccccc}
\hline Plot & $\begin{array}{c}\text { Number of trees } \\
\text { measured by the two } \\
\text { methods }\end{array}$ & $\begin{array}{c}\bar{h}_{\text {Field }} \\
(\mathrm{m})\end{array}$ & $\begin{array}{c}\bar{h}_{\text {LiDAR }} \\
(\mathrm{m})\end{array}$ & $\begin{array}{c}\Delta_{\mathrm{h}} \\
(\mathrm{m})\end{array}$ & $\begin{array}{c}R M S E_{h} \\
(\mathrm{~m})\end{array}$ \\
\hline 118D & 251 & 34.2 & 33.4 & 0.8 & 1.7 \\
43C & 434 & 31.2 & 29.8 & 1.4 & 2.1 \\
\hline $62 \mathrm{~A}$ & 299 & 31.8 & 30.5 & 1.3 & 2.2 \\
\hline
\end{tabular}

reference tree stem volumes for each plot (eq. 7):

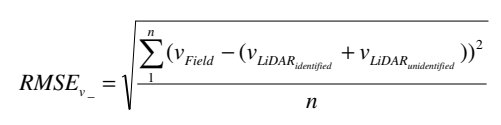

In order to assess the percentage error per plot between the total field reference stand volume $\left(V_{\text {total }}\right.$ field $)$ and the total stand LiDAR volume $\left(V_{\text {total_LiDAR }}\right)$ of both LiDAR identified and unidentified trees, we used eq. 8:

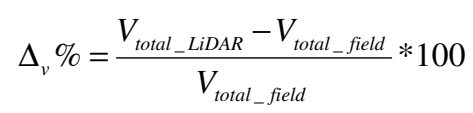

\section{Results}

Based on the $\mathrm{DbHs}$ and the heights of the field-measured trees, the ground reference stem volume of each individual tree was computed. Thus, the mean tree $\mathrm{DbH}$, the mean tree height and the mean tree stem volume, as well as the stand volume for each plot were calculated (Table 3).

Using Canopy Maxima we were able to identify and link with ground measurements 251 trees ( $61 \%$ of the total number of the field-measured trees) for the first plot (118D), 434 trees (53\%) for the second plot (plot 43C) and 299 trees (40\%) for third plot (plot 62A). The algorithm generated 63 false (i.e. nonexistent) trees for the first plot (118D), 49 false trees for the second (43C) and 36 false trees for the third (62A). These false trees were considered errors and they were not used in any computation.

For the matched trees, we calculated the height deviations $\left(\Delta_{\mathrm{h}}\right)$ between the mean height of the field-measured trees $\left(\bar{h}_{\text {Field }}\right)$ and the mean height of the automatically identified LiDAR linked trees $\left(\bar{h}_{L i D A R}\right)$ and obtained values ranging between $0.8 \mathrm{~m}$ (plot 118D) and $1.4 \mathrm{~m}$ (plot 43C). Despite the minor deviations calculated at stand level, errors for individual trees were larger: the height RMSE of the automatically identified trees from the

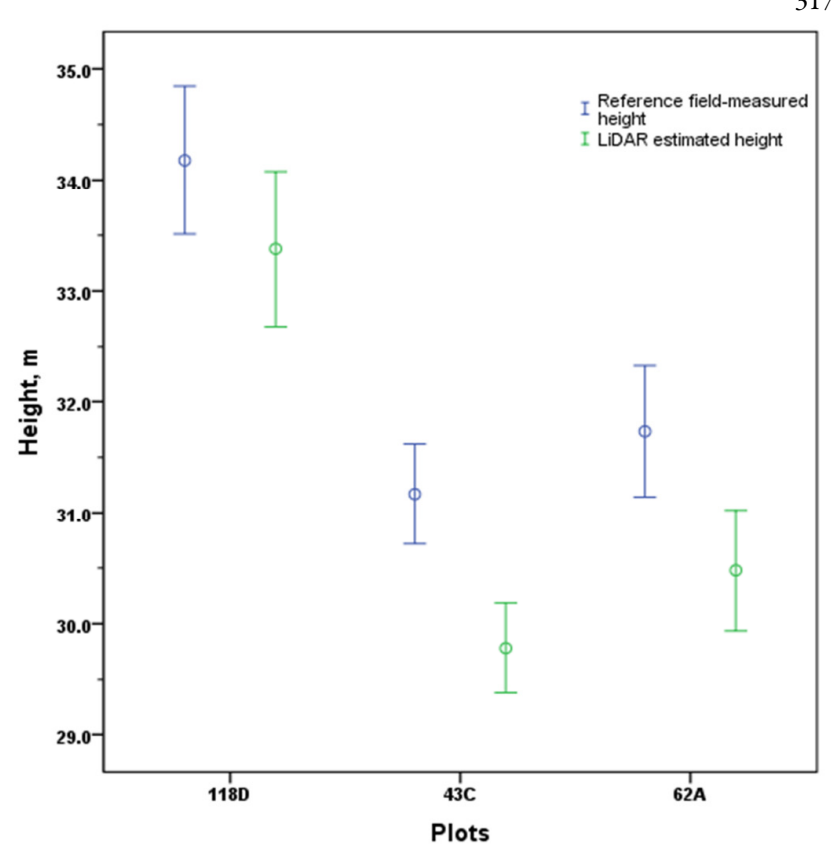

Fig. 2. The mean tree height measured on the field (blue colored legend) and the correspondent identified LiDAR one (green colored legend) for all the plots. The central circles represent the mean, whereas the vertical lines represent the 95\% confidence intervals

LiDAR data ranged from $1.7 \mathrm{~m}$ (plot 118D) to $2.2 \mathrm{~m}$ (plot 62A) (Table4).

Compared to the ground reference tree height measurements, the identified LiDAR tree heights were underestimated for all the plots (Fig. 2 and Table 4).

The identified LiDAR trees of each plot were split in half for calibration (using eq. 4) and validation purposes (using eq.5). Each half per plot was successively used once as calibration and once as validation sample, respectively. Therefore, the regression coefficients were determined and the calculated RMSE showed similar results for each validation sample of each plot (Table 5). The correlation coefficient calculated for each plot for the fieldreference stem volume of each tree and the corresponding LiDARidentified linked tree height demonstrates significant values $(\alpha<$ 5\%) between the two characteristics $(\mathrm{r}=0.75-0.82)$ (Fig. 3).

With respect to the highest $R^{2}$, the best model equation for each plot was chosen for further stem volume computation of the identified and unidentified LiDAR trees.

Upon comparing the mean volume for the population of the LiDAR identified and linked trees $\left(\bar{v}_{L i D A R}\right)$ and the mean volume for the population of the corresponding reference field trees $\left(\bar{v}_{\text {Field }}\right)$ for each plot, we found no statistically significant differences between the means of the two population (Wilcoxon test) (Table 6).

The deviations $\left(\Delta_{v}\right)$ between the mean field-reference stem volume $\left(\bar{v}_{\text {Field }}\right)$ and the mean stem volume of the identified linked trees based on the LiDAR $\left(\bar{v}_{L i D A R}\right)$ dataset ranged between $0.04 \mathrm{~m}^{3}$ (plot 43C) and $0.07 \mathrm{~m}^{3}$ (plot 62A). The minor calculated deviations of LiDAR-estimated volumes in this case were highlighted in smaller values of RMSE, ranging from $0.5 \mathrm{~m}^{3}$ (plots 43C and 62A) to $0.7 \mathrm{~m}^{3}$ (plot 118D) and are comparable 
318

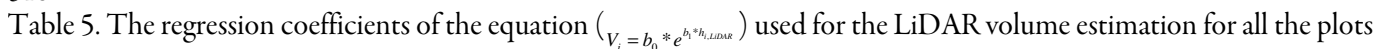

\begin{tabular}{|c|c|c|c|c|c|c|}
\hline \multirow{2}{*}{ Plot } & \multicolumn{2}{|c|}{ Number of trees for } & \multirow[b]{2}{*}{$b_{0}$} & \multirow[b]{2}{*}{$b_{1}$} & \multirow[b]{2}{*}{$\mathrm{R}^{2}$} & \multirow[b]{2}{*}{$R M S E_{\mathrm{v}}$} \\
\hline & calibration & validation & & & & \\
\hline \multirow{2}{*}{ 118D } & 126 & 125 & 0.055 & 0.109 & 0.809 & 0.7 \\
\hline & 125 & 126 & 0.070 & 0.102 & 0.739 & 0.7 \\
\hline \multirow{2}{*}{$43 \mathrm{C}$} & 217 & 217 & 0.024 & 0.131 & 0.778 & 0.5 \\
\hline & 217 & 217 & 0.031 & 0.122 & 0.768 & 0.5 \\
\hline \multirow{2}{*}{$62 \mathrm{~A}$} & 149 & 150 & 0.069 & 0.102 & 0.685 & 0.5 \\
\hline & 150 & 149 & 0.069 & 0.102 & 0.715 & 0.5 \\
\hline $118 \mathrm{D}$ & & 251 & & & & 0.8 \\
\hline $43 \mathrm{C}$ & 984 & 434 & 0.042 & 0.115 & 0.761 & 0.5 \\
\hline $62 \mathrm{~A}$ & & 299 & & & & 0.5 \\
\hline
\end{tabular}

Table 6. The mean ground reference stem volume $\left(\bar{v}_{\text {Field }}\right)$ and the mean stem volume estimated on LiDAR data $\left(\bar{v}_{\text {LDAR }}\right)$ determined for the linked trees, the errors of LiDAR volume represented by their deviations from the field volumes $\left(\Delta_{\mathrm{v}}\right)$ and the root mean square error $\left({ }_{R M S E_{v}}\right)$ and the statistical significance based on Wilcoxon test

\begin{tabular}{cccccccc}
\hline Plot & $\begin{array}{c}\text { Number of trees } \\
\text { measured by the two } \\
\text { methods }\end{array}$ & $\bar{v}_{\text {Field }}\left(\mathrm{m}^{3}\right)$ & $\bar{v}_{\text {LiDAR }}\left(\mathrm{m}^{3}\right)$ & $\begin{array}{c}\Delta_{\mathrm{v}} \\
\left(\mathrm{m}^{3}\right)\end{array}$ & $\mathrm{R}_{\text {value }}\left(\mathrm{m}^{3}\right)$ & $\mathrm{Z}_{\text {value }}$ & $\mathrm{Z}_{\text {value } 95 \%}$ \\
\hline $118 \mathrm{D}$ & 251 & 2.47 & 2.40 & 0.07 & 0.7 & -0.353 & 0.724 \\
$43 \mathrm{C}$ & 434 & 1.43 & 1.39 & 0.04 & 0.5 & -0.118 & 0.906 \\
\hline $62 \mathrm{~A}$ & 299 & 1.78 & 1.71 & 0.07 & 0.5 & -1.079 & 0.28 \\
\hline
\end{tabular}

Table 7. The regression coefficients of the equation used for the height trees estimation of LiDAR unidentified trees for all the plots

\begin{tabular}{lcccc}
\hline & \multicolumn{3}{c}{ Equation regression coefficients } \\
Plot & \multicolumn{3}{c}{$\ln h_{\text {LDAR }}=a_{0}+a_{1} * D b H^{a_{2}}$} & \\
\cline { 2 - 4 } & $a_{0}$ & $a_{1}$ & $a_{2}$ & \\
\hline $118 \mathrm{D}$ & 3.635 & -799.039 & -2.379 & 0.77 \\
$43 \mathrm{C}$ & 4.265 & -5.298 & -0.516 & 0.64 \\
$62 \mathrm{~A}$ & 3.663 & -80.381 & -1.597 & 0.55 \\
\hline
\end{tabular}

with those obtained by using the data from all the plots to calibrate eq. 4 (i.e. $0.5-0.8 \mathrm{~m}^{3}$ ) (Tables 5 and 6).

The LiDAR tree stem volumes, based on the automatic tree identification algorithm compared with ground reference tree stem volumes, were underestimated for all the plots. The LiDAR identified tree heights were more evidently underestimated compared to the field-measured tree heights (Fig. 4 and Table 6).

The correlation coefficient between the $\mathrm{DbH}$ and the LiDAR height for the linked trees shows significant values $(\alpha<$ $5 \%)$ between the two characteristics $(\mathrm{r}=0.67-0.80)$ for each plot. Based on this correlation, the regression coefficients determined for each plot and on eq. 6 (Table 7 and Fig. 5), we were able to estimate the heights of the LiDAR unidentified trees. These heights were then used in the estimation of the LiDAR unidentified tree stem volume. The total LiDAR stand volume was calculated by summing the identified and the LiDAR unidentified stem volume of the trees.

By comparing the ground reference mean stem volume for each plot with the total LiDAR-estimated volume (which considered both the identified and unidentified trees) we notice that the deviations $\left(\Delta_{\mathrm{v}}\right)$ of the mean ground reference tree stem volume $\left(\bar{v}_{\text {Field }}\right)$ and the mean LiDAR-estimated volume $\left(\bar{v}_{L i D A R}\right)$ ranged between $-0.02 \mathrm{~m}^{3}$ (plot $43 \mathrm{C}$ ) and $-0.08 \mathrm{~m}^{3}$ (plot 62A) (Table 8). Despite this, the total LiDAR estimated stand volume is slightly higher than the ground reference volume
Table 8 . The mean field reference stand volume $\left(\bar{v}_{\text {Field }}\right)$ and the mean stand volume estimated on LiDAR data $\left({\overline{v_{L D A R}}}\right)$ determined for all the plots (per hectare) and the errors of LiDAR volume represented by their deviations from the field reference volumes $\left(\Delta_{\mathrm{V}_{-}}\right)$and the root mean square error $\left({ }_{R M S E_{v}}\right)$

\begin{tabular}{lccccc}
\hline Plot & $\begin{array}{c}\text { Number of trees } \\
\text { measured by the two } \\
\text { methods }\end{array}$ & $\begin{array}{c}\bar{v}_{\text {Field }} \\
\left(\mathrm{m}^{3}\right)\end{array}$ & $\begin{array}{c}\bar{v}_{\text {LDAR }} \\
\left(\mathrm{m}^{3}\right)\end{array}$ & $\begin{array}{c}\Delta_{\mathrm{v}_{-}} \\
\left(\mathrm{m}^{3}\right)\end{array}$ & $\begin{array}{c}\text { RMSE } \\
\left(\mathrm{m}^{3}\right)\end{array}$ \\
\hline 118D & 414 & 1.92 & 1.99 & -0.07 & 0.6 \\
43C & 820 & 1.07 & 1.09 & -0.02 & 0.4 \\
\hline $62 \mathrm{~A}$ & 748 & 1.18 & 1.26 & -0.08 & 0.4 \\
\hline
\end{tabular}

for each plot. The estimation of mean stem volume based on the LiDAR data resulted in smaller values of RMSE, ranging from $0.4 \mathrm{~m}^{3}$ (plot 43C and 62A) to $0.6 \mathrm{~m}^{3}$ (plot 118D) than when considering only the identified trees for both datasets (reference field trees and linked LiDAR-identified trees) (Fig. 6 and Table 8).

The percentage error (eq. 8) of the total LiDAR stand volume (calculated as a sum of LiDAR-identified and unidentified tree stem volumes) compared with the total ground reference stand volume ranged between 1.79\% (plot 43C) and $7.18 \%$ (plot 62A) (Table 9).

\section{Discussion}

In this study, we applied a methodology for estimating individual tree height, stem and stand volumes based on LiDAR data and field measurements for multilayered spruce stands of various ages. Automatic tree identification and tree height extraction from LiDAR data was performed using the segmentation of the CHM based on a variable window-size algorithm calibrated with locally determined tree height to crown diameter regression equations. Individual tree volumes were determined from ground 

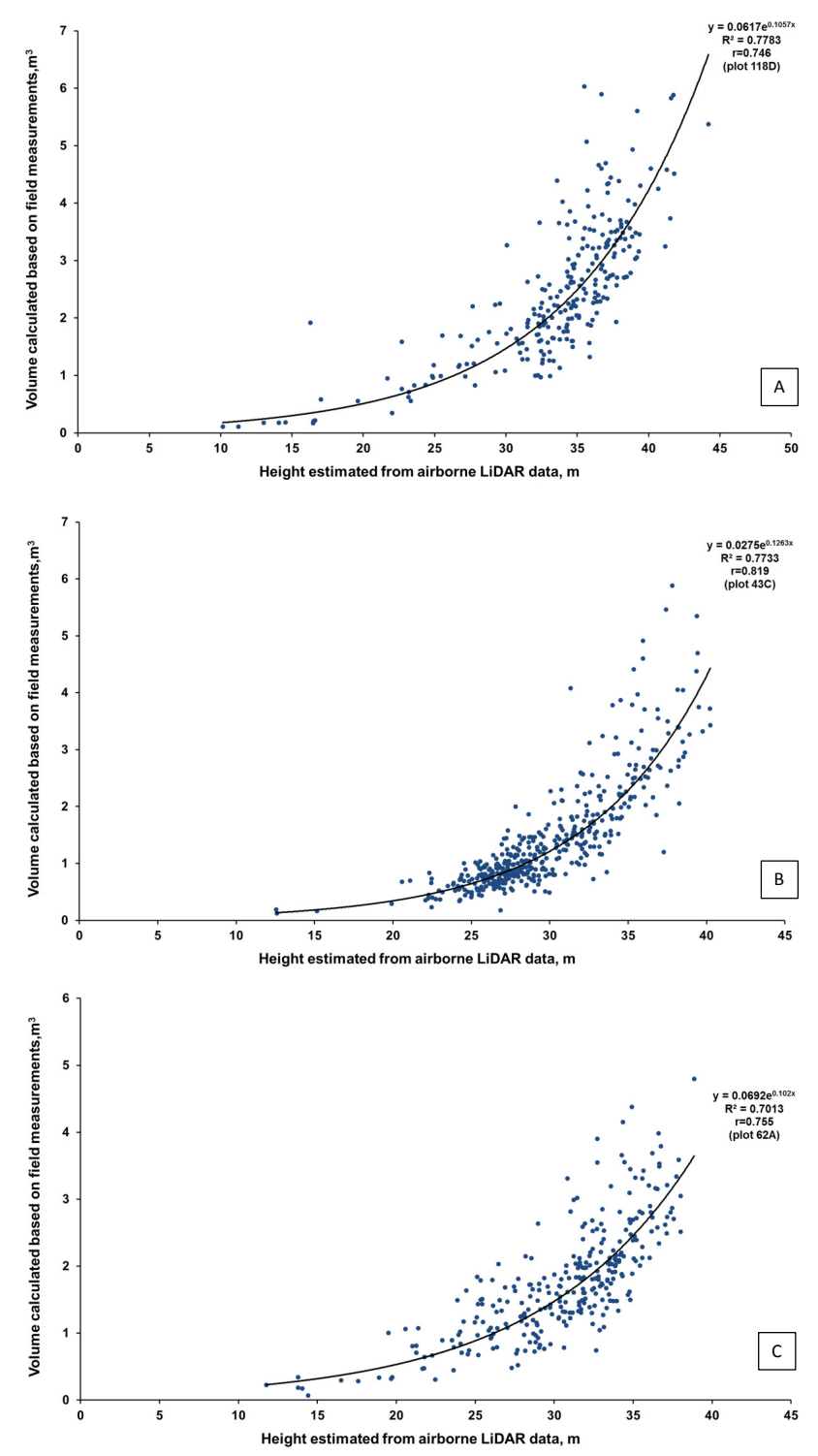

Fig. 3. The correlation between the field reference tree stem volume and the correspondent estimated linked tree height identified based on LiDAR data for plot $118 \mathrm{D}(\mathrm{A})$, plot 43C(B), plot 62A (C)

measurements using a double logarithmic equation based on $\mathrm{DbH}$ and height, and compared with the LiDAR-estimated volume determined through empirical modelling of ground reference tree stem volume and LiDAR height for each linked tree.

The number of trees correctly detected by the Canopy Maxima algorithm was 251 trees (61\%) of the total number of the field-measured trees for the first plot (118D), 434 trees (53\%) for the second plot (plot 43C) and 299 trees (40\%) for the last plot (plot 62A). The rather low detection rate is mostly attributable to the algorithm's drawback in identification of upper-most canopy trees, and is generally comparable to the rate in previously reported studies in similar forest conditions. The rate of tree detection for the identified trees by Kraft classes is provided in Table 10 . Solberg et al. (2006), investigating a heterogeneous spruce

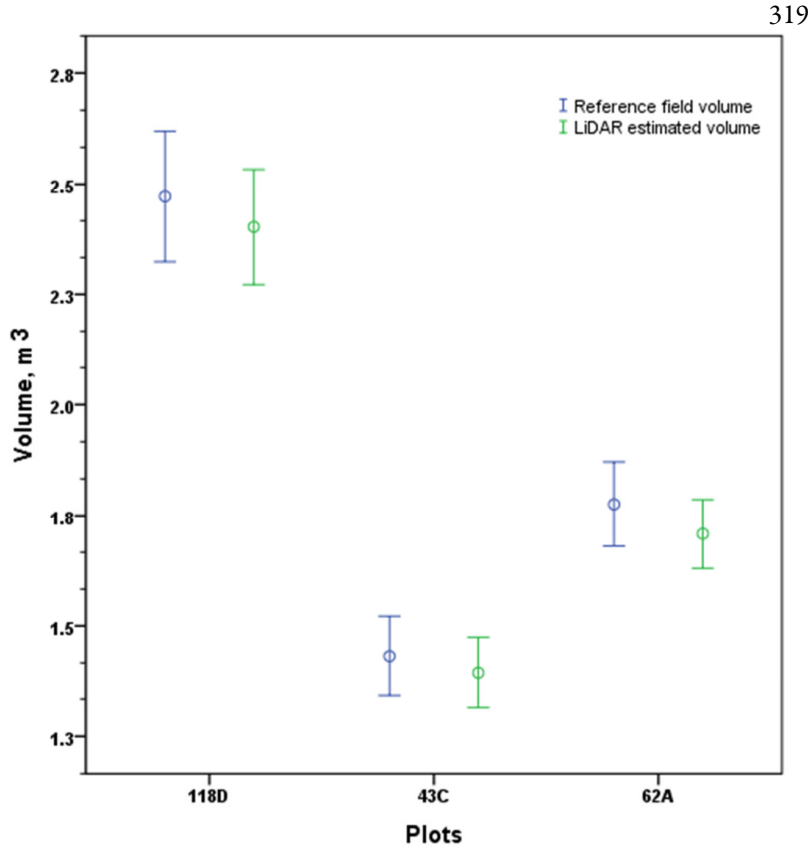

Fig. 4. The mean field reference stem volume (blue colored legend) and the mean estimated LiDAR volume of the corresponding identified linked trees (green colored legend) for all the plots. The central circles represent the mean, whereas the vertical lines represent the $95 \%$ confidence intervals

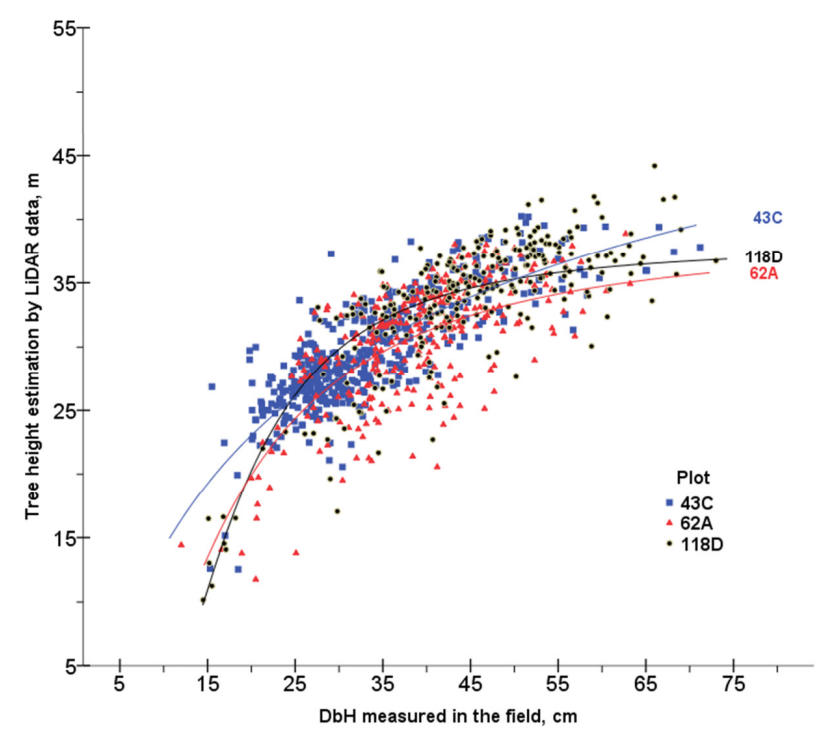

Fig. 5. The correlation between the $\mathrm{DbH}$ measured in the field and the correspondent estimated linked tree height identified based on LiDAR data for all the plots

forest, used LiDAR data to correctly identify $93 \%$ of dominant trees, $63 \%$ of co-dominant trees, $38 \%$ of the subdominant trees, $19 \%$ of suppressed trees and $9 \%$ of dead trees. Ene et al. (2012) detected approximately 46-50\% of the total number of trees in a structurally heterogeneous boreal forest dominated by Norway spruce and Scots pine. Edson and Wing (2011) used Fusion software to identify trees in structurally different stands, not by employing an automatic local maxima algorithm but instead by 
320

Table 9. The percentage error of the estimated stand volume based on LiDAR data from the total stand field reference volume

\begin{tabular}{|c|c|c|c|c|c|c|c|c|}
\hline Plot & $\begin{array}{l}\text { Area } \\
\text { (ha) }\end{array}$ & $\begin{array}{l}\text { Total ground } \\
\text { reference } \\
\text { volume }\left(\mathrm{m}^{3}\right)\end{array}$ & $\begin{array}{c}\text { LiDAR } \\
\text { volumeof the } \\
\text { identified trees } \\
\left(\mathrm{m}^{3}\right)\end{array}$ & $\begin{array}{l}\text { Ground reference } \\
\text { volumeof the } \\
\text { LiDARlinked } \\
\text { trees }\left(\mathrm{m}^{3}\right)\end{array}$ & $\begin{array}{c}\text { Percentageerror } \\
\text { ofthevolume } \\
\text { of thelinkedtrees } \\
\text { (ground referenced } \\
\text { andLiDARlinked } \\
\text { trees)(\%) }\end{array}$ & $\begin{array}{l}\text { LiDAR } \\
\text { volume of the } \\
\text { unidentified } \\
\text { trees }\left(\mathrm{m}^{3}\right)\end{array}$ & $\begin{array}{c}\text { LiDAR } \\
\text { total volume } \\
\left(\mathrm{m}^{3}\right)\end{array}$ & $\begin{array}{l}\text { Percentageerrorofthe } \\
\text { LiDAR total volume } \\
\text { compared to total } \\
\text { groundreference } \\
\text { volume(\%) }\end{array}$ \\
\hline 0 & 1 & 2 & 3 & 4 & $\begin{array}{c}5 \\
\frac{(3)-(4) * 100)}{(4)}\end{array}$ & 6 & 7 & $\begin{array}{c}8 \\
\left(\frac{(7)-(2)}{(2)} * 100\right)\end{array}$ \\
\hline $118 \mathrm{D}$ & 1 & 792.89 & 603.07 & 620.34 & -2.78 & 221.82 & 824.89 & 4.03 \\
\hline $43 \mathrm{C}$ & 1 & 875.95 & 605.09 & 621.31 & -2.61 & 286.61 & 891.70 & 1.79 \\
\hline $62 \mathrm{~A}$ & 1 & 880.50 & 510.76 & 530.99 & -3.81 & 432.99 & 943.75 & 7.18 \\
\hline
\end{tabular}

Table 10. The rate of tree detection by Kraft classes of the identified Lidar trees for all the plots

\begin{tabular}{|c|c|c|c|c|c|c|c|c|c|c|c|}
\hline \multirow{3}{*}{ Plot } & \multirow{3}{*}{$\begin{array}{l}\text { Number of trees } \\
\text { identified on } \\
\text { LiDAR data }\end{array}$} & \multicolumn{10}{|c|}{ LiDAR identified trees in the Kraft class } \\
\hline & & \multicolumn{2}{|l|}{ I } & \multicolumn{2}{|l|}{ II } & \multicolumn{2}{|c|}{ III } & \multicolumn{2}{|l|}{ IV } & \multicolumn{2}{|c|}{$\mathrm{V}$} \\
\hline & & $\begin{array}{c}\text { Number of } \\
\text { trees }\end{array}$ & $\%$ & $\begin{array}{c}\text { Number of } \\
\text { trees }\end{array}$ & $\%$ & $\begin{array}{c}\text { Number of } \\
\text { trees }\end{array}$ & $\%$ & $\begin{array}{c}\text { Number of } \\
\text { trees }\end{array}$ & $\%$ & $\begin{array}{c}\text { Number of } \\
\text { trees }\end{array}$ & $\%$ \\
\hline $118 \mathrm{D}$ & 251 & 91 & 36 & 117 & 47 & 26 & 10 & 14 & 6 & 3 & 1 \\
\hline $43 \mathrm{C}$ & 434 & 76 & 18 & 235 & 54 & 101 & 23 & 13 & 3 & 9 & 2 \\
\hline $62 \mathrm{~A}$ & 299 & 132 & 44 & 102 & 34 & 43 & 14 & 11 & 4 & 11 & 4 \\
\hline
\end{tabular}

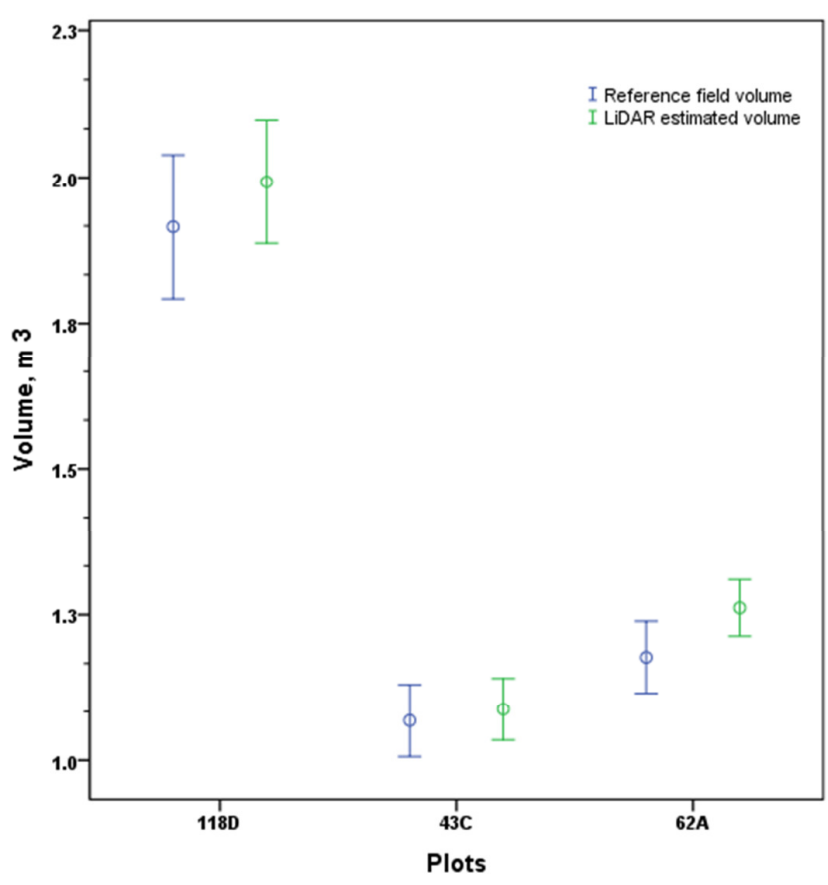

Fig. 6. The mean field reference stand volume (blue colored legend) and the mean estimated total LiDAR volume (green colored legend) for all the plots. The central circles represent the mean, whereas the vertical lines represent the $95 \%$ confidence intervals

performing manual identification of the trees in the LDV Fusion visualization window using the LiDAR point cloud. They reported a detection rate of $44 \%$. However, their accuracy improved when using watershed segmentation (91\%) or the TreeVaW software (59\%).

Several factors influence the accuracy of tree detection based on LiDAR data. For raster-based segmentation of $\mathrm{CHM}$, as in our case, of high importance is the resolution and the quality of the raster-modelled canopy surface. A very fine $\mathrm{CHM}$ resolution increases the potential for false positives, while a too-coarse resolution leads to an increased number of valid but undetected trees (Solberg et al., 2006; Ene et al., 2012). In our study, we used a resolution of $0.5 \mathrm{~m}$, which is consistent with those used in similar studies (Hyyppä et al., 2001; Popescu et al., 2004; Lindberg and Hollaus, 2012).

To remove small variations in the $\mathrm{CHM}$ model that can also lead to false detections, we used a median $3 \times 3$ algorithm filter in creating the CHM, thus obtaining a smoothed canopy surface. This algorithm is implemented in Fusion and has been proven to generate more accurate results than the mean filter (Edson and Wing, 2011).

In dense and multilayered stands, the rate of tree detection decreases as the suppressed trees fall below the CHM, which is obtained by interpolating the points belonging mostly to dominant and co-dominant trees. Thus, the trees below the canopy model that exists in the field will be invisible to the model (Edson and Wing, 2011).

The root mean square error (RMSE) between the individual heights measured in the field and the corresponding heights identified by the LiDAR data was 1.7-2.2 meters. The LiDARestimated heights were slightly smaller than the groundmeasured heights $\left(\Delta_{\mathrm{h}} 0.8 \mathrm{~m}\right.$ for plot $118 \mathrm{D}$ to $1.4 \mathrm{~m}$ for plot $43 \mathrm{C})$. The results are consistent with those obtained by other authors in similar forest conditions. Ene et al. (2012) used areabased stem number estimates to guide tree crown delineation from CHMs, applying a marker-based watershed algorithm. Strong linear correlation was found between tree level estimates of the height ( $r=0.97$ for spruce, $r=0.95$ for pine). The mean plot height was underestimated in pine-dominated plots, with $0.96 \mathrm{~m}$, and in spruce-dominated plots, with $0.5 \mathrm{~m}$. A strong linear correlation was found between the ALS- and the fieldbased mean plot heights $(r=0.93$ for spruce-dominated plots, $r$ $=0.89$ for pine-dominated plots).

Solberg et al. (2006) found a strong correlation between the LiDAR-estimated tree heights and ground-based measurements $\left(\mathrm{R}^{2}=0.92, \mathrm{RMSE}=1.0, \mathrm{n}=38\right)$. Initially, their $\mathrm{CHM}$ produced tree heights that were on average $62 \mathrm{~cm}$ below the correct values. Their solution to this was to lift the entire CHM by the corresponding percentile value of the residuals.

Persson et al. (2002) used a slope-based segmentation for the $\mathrm{CHM}$ and for retracting tree height and tree crown in Picea abies and Pinus sylvestris dominated stands. The rate of detected trees 
under this method was $71 \%$ and the reported accuracy included an RMSE $=0.63$ for tree height estimation (correlation coefficient of 0.99 ).

Popescu et al. (2003) performed tree height estimations based on single tree crown identification using a variable window size for local filtering in a heterogeneous forest (deciduous, coniferous and mixed stands of varying age classes). Linear regression was used to develop equations relating LiDARestimated parameters to field inventories (i.e., prediction of crown size based on tree height). The variable window-size algorithm performed better for predicting heights of dominant and co-dominant trees $\left(\mathrm{R}^{2}\right.$ values $\left.0.84-0.85\right)$.

Edson and Wing (2011) found tree height differences from field-measured heights for Fusion, TreeVaW and watershed segmentation of $-0.09 \mathrm{~m}$ (SD 2.43), $0.28 \mathrm{~m}$ (SD 1.86) and 0.22 $\mathrm{m}(\mathrm{SD} 2.45)$, respectively.

Tree height underestimation is widely reported in LiDAR studies and generally attributed in the case of boreal forests to a more frequent laser sampling of the crown shoulders than of the tree apex, resulting in lower canopy heights (Popescu et al., 2003). Using a denser laser pulse density might increase the rate of apex hits and thereby the accuracy of the estimation of tree heights.

The height of the trees was calculated as the distance between the $\mathrm{Z}$ positions of the local maximas considered as the top of the trees and the corresponding perpendicular points from the DTM. Thus, the accuracy of deriving the ground elevation directly affects the accuracy of measured heights (Popescu $e t a l$., 2004). We obtained the DTM through an automatic ground classification algorithm of the QCoherent LP360 software based on the Adaptive TIN Ground Filter method. Although a DTM accuracy assessment was not performed, by interpreting the obtained tree heights, we can judge that the DTM accuracy is rather satisfactory.

We did not take into account errors that might be attributed to ground measurements. The vendor-reported error for a Vertex IV hypsometer is $0.1 \mathrm{~m}$. This error can slightly increase in the case of steep terrain, as was the case for our plots. In addition, some measurement faults might have occurred due to operator error, given the high number of total sampled trees (i.e., 1982).

In creating the CHM, we used all the first-return LiDAR pulses except those used to obtain the DTM. In such cases, the CHM generates a slightly lower surface, which can contribute to underestimating tree heights with LiDAR (Popescu et al., 2004). Thus, a further refinement of the CHM interpolation method might lead to better estimates of LiDAR heights.

Concerning the LiDAR volume estimation, by comparing the ground reference tree volume with the corresponding LiDAR estimated volume, we achieved an RMSE of 0.5 and $0.7 \mathrm{~m}^{3}$. The LiDAR volume of the identified trees represents $76 \%$ (plot 118D), $69 \%$ (plot 43C) and 58\% (plot 62A) of the total stand volume calculated based on field measurements. The RMSE was slightly smaller when we compare the ground reference tree stem volume with the total LiDAR-estimated volume, considering both the identified and unidentified trees $\left(0.4-0.6 \mathrm{~m}^{3}\right)$. The percentage error of the total LiDAR stand volume compared with the total stand reference volume was less than $8 \%$ (Table 9). These results indicate the robustness of the applied methodology. The results are thus comparable with those reported by other authors, although a direct comparison might not be appropriate in most of the cases considering the various approaches used for stem and stand volume estimation. In the case of single trees segmentation methods, the LiDAR-estimated volumes are obtained by using LiDAR-derived parameters, such as tree height and crown. Different heights are used to calculate the volumes (e.g., mean height, Lorey's original height, percentile heights) and varying regression equations and functions. We estimated the stand volume based on LiDAR data through empirical modelling of ground reference tree stem volume and LiDAR height for each linked tree.

Persson et al. (2002) calculated the stem volume for LiDARdetected trees using volume functions, with stem diameter and laser height as variables. The stem diameter was a predicted function of laser tree height and laser crown diameter (RMSE of $3.8 \mathrm{~cm}$ accounting for $10 \%$ of the mean value). The RMSE of the volume estimates was $0.21 \mathrm{~m}^{3}$, corresponding to $22 \%$ of the mean value. Hyyppä et al. (2001) calculated stand volume based on tree height measurements and area crown measurements of each single tree using a formula that estimated volume using stem diameter and the height of the tree. The stem diameter was calculated with consideration to the strong correlation between height and stem diameter. They estimated the stem volume with a standard error of $18.5 \mathrm{~m}^{3} \mathrm{ha}^{-1}(10.5 \%)$.

\section{Conclusions}

After analyzing, based on the results obtained in this study, the possibility of individual tree extraction and stand volume estimation for the considered Norway spruce plots, the following conclusions can be made:

- By running the automatic identification algorithm implemented in Fusion, customized with our proper local coefficients, we obtained a tree rate detection of $40-61 \%$ for the considered field plots.

- The automatic tree height automatically identified based on the LiDAR data is smaller than the corresponding field-measured tree height. The RMSE between the tree heights identified based on LiDAR data and the corresponding field-measured tree height ranged from $1.7 \mathrm{~m}-2.2 \mathrm{~m}$.

- After comparing the mean volume for the population of the LiDAR-identified and linked trees to the mean ground volume for the population of the corresponding reference field trees, we did not uncover any statistically significant difference between the two means $(\mathrm{p}>0.05)$.

- A method was proposed to estimates the height and, in a subsequent step, the stem volume of the unidentified trees by the LiDAR data based on a regression equation of the estimated LiDAR identified linked tree height and their corresponding field- measured $\mathrm{DbH}$.

- The results show that the method used to estimate the height of individual trees and stand volume based on the LiDAR dataset and ground measurements indicates the proportion of the stand volume that could be estimated using LiDAR techniques. The encouraging results of the study, as well as the relatively small percentage errors of the LiDAR estimated stand volume as compared with the total stand ground reference volume (1-7\%) allows for the implementation of the method in similar conditions and with satisfactory accuracy in order to estimate tree heights and spruce stands volumes. 


\section{Acknowledgments}

This work was supported by Romanian Authority for Research in Core Program for Forestry - GEDEFOR, project PN09460113.

\section{References}

Anderson RS, Bolstad PV (2013). Estimating aboveground biomass and average annual wood biomass increment with airborne leaf-on and leafoff lidar in great lakes forest types. Northern Journal of Applied Forestry 30(1):16-22.

Apostol B, Petrila M, Lorenț A, Gancz V, Creț A (2011). Potential use of airborne LiDAR technology by the integration of remote sensing and terrestrial datasets for forests assessment and mapping in Romania. Proceedings to Symposium "Forest and Sustainable Development". Editura Universitatii “Transilvania” din Braşov pp 513-518.

Apostol B, Petrila M, Lorenț A, Gancz V, Silaghi D (2012). Estimarea volumului de masă lemnoasă pe picior la arborete de molid utilizând date LiDAR aeropurtat şi măsurători terestre [The assessment of Norway spruce stands volume using airborne LiDAR data and in situ field measurements]. Revista Pădurilor 2:14-22.

Dorren L, Maier B, Berger F (2006). Assessing protection forest structure with airborne laser scanning in steep mountainous terrain. Proceedings of Workshop on 3D Remote Sensing in Forestry, 1415 February2006, Vienna, Session 8b pp 238-242.

Edson C, Wing MG (2011). Airborne light detection and ranging(LiDAR) for individual tree stem location, height, and biomass measurements. RemoteSensing 3:24942528, doi:10.3390/rs3112494.

Ene L, NæssetE, Gobakken T (2012). Single tree detection in heterogeneous boreal forests using airborne laser scanning and area-based stem number estimates. International Journal of RemoteSensing 33(16):5171-5193.

Eysn L, Hollaus M, Lindberg E, Berger F, Monnet JM, Dalponte M, Kobal M, Pellegrini M, Lingua E, Mongus D, Pfeifer N (2015). A Benchmark of Lidar-Based Single Tree Detection Methods Using Heterogeneous Forest Datafrom the AlpineSpace. Forests 6: 1721-1747.

Eysn L, Hollaus M, Schadauer K, Pfeifer N (2012). Forest Delineation Based on Airborne LIDARData. RemoteSensing 4:762-783.

García M, Riaño D, Chuvieco E, Danson FM (2010). Estimating biomass carbon stocks for a Mediterranean forest in central Spain using LiDAR height and intensity data. Remote Sensing of Environment 114:816830.

Giurgiu V, Decei I, Drăghiciu D (2004). Metode şi tabele dendrometrice [Forest Mensuration Methods and Tables]. Editura Ceres, Bucuresti.

Goodwin NR, Coops NC, Culvenor DS (2006). Assessment of forest structure with airborne LiDAR and the effects of platform altitude, RemoteSensing of Environment 103(2): 140-152.

Hall SA, Burke IC, Box DO, Kaufmann MR, StokerJM (2005). Estimating stand structure using discrete-return lidar: an example from low density fire prone ponderosa pine forests. Forest Ecology and Management 208:189-209.

Hansen EH, Gobakken T, Bollandsås OM, Zahabu E, Næsset E (2014). Modeling Aboveground Biomass in Dense Tropical Submontane Rainforest Using Airborne Laser Scanner Data. Remote Sensing 7:788807.
Hernández-Stefanoni JL, Johnson KD, Cook BD, Dupuy JM, Birdsey R, Peduzzi A, Tun-Dzul F (2015). Estimating species richness and biomass of tropical dry forests using LIDAR during leaf-on and leaf-off canopy conditions. Applied Vegetation Science 18(4):724732.

Heurich M, Thoma F (2008). Estimation of forestry stand parameters using laser scanning data in temperate, structurally rich natural European beech (Fagus sylvatica) and Norway spruce (Picea abies) forests. Forestry 81(5):645-661.

Holmgren J, Persson A (2004). Identifying species of individual trees using airbornelaser scanner. Remote Sensing of Environment 90(4):415-423.

Hyde P, Dubayah R, Peterson B, BlairJB, Hofton M, Hunsaker C, Knox R, Walker W (2005). Mapping forest structure for wildlife habitat analysis using waveform lidar: Validation of montane ecosystems. Remote Sensing of Environment 96(3-4):427-437.

Hyyppä J, Kelle O, Lehikoinen M, Inkinen M (2001). A segmentationbased method to retrieve stem volume estimates from 3-D tree height models produced by laser scanners, IEEE Transactions on Geoscience and Remote Sensing 39:969-975.

IFER(1999-2006). Field-Map Technology.

Jennings SB, Brown ND, Sheil D (1999). Assessing forest canopies and understorey illumination: Canopy closure, canopy cover and other measures. Forestry 72(1):59-73.

Kraft G (1884). Beiträge zur Lehre von Durchforstungen, Schlagstellungen und Lichtungshieben [On the methodology of thinnings, shelterwood cuttings and heavy release operations]. Hanover.

Kramer HA, Collins BM, Kelly M, Stephens SL (2014). Quantifyingladder fuels: A new approach using LiDAR Forests 5:1432-1453

Lefsky MA, Hudak AT, Cohen WB, Acker SA (2005). Patterns of covariance between forest stand and canopy structure in the Pacific Northwest. RemoteSensing of Environment 95:517-531.

Lim K, Treitz P, Wulder M, St-Onge B, Flood M (2003). LiDAR remote sensing of forest structure. Progress in physical geography 27(1):88-106.

Lindberg E, Hollaus M (2012). Comparison of methods for estimation of stem volume, stem number and basal area from airborne laser scanning data in a hemi-boreal forest. Remote Sensing 4:1004-1023.

Magnussen S, Boudewyn P (1998). Derivations of stand heights from airborne laser scanner data with canopy-based quantile estimators. Canadian Journal of Forest Research 28:1016-1031.

Maguya AS, Junttila V, Kauranne T (2014). Algorithm for extracting digital terrain models under forest canopy from airborne LiDAR data. Remote Sensing 6:6524-6548.

McGaugheyJ (2014). FUSION/LDV: Software for LIDARData Analysis and Visualization.

Middleton WEK, Spilhaus AF (1953). Meteorological Instruments. University of Toronto Press. 3rdEdition.

Montealegre AL, Lamelas MT, Tanase MA, de la Riva J (2014). Forest Fire Severity Assessment Using ALS Data in a Mediterranean Environment. RemoteSensing 6(5):4240-4265.

Naesset E (1997). Estimating timber volume of forest stands using airborne laser scanner data. Remote Sensing of Environment 61(2):246-253.

Parent J, Volin JC (2014). Assessing the potential for leaf-off LiDAR data to model canopy closure in temperate deciduous forests. ISPRS Journal of Photogrammetryand Remote Sensing 95:134145. 
Persson A, Holmgren J, Söderman U (2002). Detecting and measuring individual trees using an airborne laser scanner. Photogrammetric Engineering and RemoteSensing 68:925-932.

Petrila M, Apostol B, Gancz V, Lorenț A, Silaghi D (2012a). Forest biomass estimation by the use of airborne laser scanning and in situ field map measurement in a spruce forest stand. Folia Forestalia Polonica, series A 54(2):84-93.

Petrila M, Gancz V, Apostol B, Lorenț A (2012b). Comparing height of individual spruce trees determined on LiDAR data and reference field measurements. In: Perakis K, Moysiadis A (Eds). EARSeL Symposium 2012, Mykonos Island, Greece pp 251-262.

Popescu SC, Wynne RH, Nelson RF (2002). Estimating plot-level tree heights with lidar: local filtering with a canopy-height based variable window size. Computers and Electronics in Agriculture 37(1-3):71-95

Popescu SC, Wynne RH, Nelson RF (2003). Measuring individual tree crown diameter with LiDAR and assessing its influence on estimating forest volume and biomass. Canadian Journal Remote Sensing 29(5):564-577.

Popescu SC, Wynne R, Scrivani J (2004). Fusion of small-footprint LiDAR and multispectral data to estimate plot-level volume and biomass in deciduous and pine forests in Virginia. USA. Forest Science 50:551-565.

Popescu SC, Wynne R (2004). Seeing the trees in the forest: using LiDAR and multispectral data fusion with local filtering and variable window size for estimating tree height. Photogrammetric Engineering and Remote Sensing 70:589-604.

Popescu SC (2007). Estimating biomass of individual pine trees using airbornelidar. Biomass and Bioenergy 31 (9): 646-655.

Popescu SC, Zhao K (2008). A voxel-based lidar method for estimating crown base height for deciduous and pine trees. Remote Sensing of Environment 112(3):767-781.

Popescu-Zeletin I (1957). Tabele dendrometrice [Forest Mensuration Tables].Editura Agrosilvica de stat. Bucuresti.

Reitberger J, Krzystek P, Stilla U (2008). Analysis of full waveform LIDAR data for the classification of deciduous and coniferous trees. International Journal of RemoteSensing29(5):1407-1431.

Ruiz LA, Hermosilla T, Mauro F, Godino M (2014). Analysis of the Influence of Plot Size and LiDAR Density on Forest Structure AttributeEstimates. Forests 5:936-951
Sačkov I, Kardoš M (2014). Forest delineation based on LiDAR data and vertical accuracy of the terrain model in forest and non-forest area. Annals of Forest Research 57(1):119-136.

Shendryk I, Hellström M, Klemedtsson L, Kljun N (2014). Low-Density LiDAR and Optical Imagery for Biomass Estimation over Boreal Forest in Sweden. Forests 5:992-1010.

Skowronski NS, Lister AJ (2012). The utility of LiDAR for large area forest inventory applications. Moving from Status to Trends: Forest Inventory and Analysis Symposium pp 410-413.

Solberg S, Naesset E, Bollandsas OM (2006). Single tree segmentation using airborne laser scanner data in a structurally heterogeneous spruce forest. Photogrammetric Engineering and Remote Sensing 72(12):13691378.

Strîmbu VF, Strîmbu BM (2015). A graph-based segmentation algorithm for tree crown extraction using airborne LiDAR data. ISPRS Journal of Photogrammetry and Remote Sensing 104:30-43.

Tan S, Haider A (2010). A comparative study of polarimetric and nonpolarimetric lidar in deciduous-coniferous tree classification. International Geoscience Remote Sensing Symposium, IGARSS 2010, July 25-30,2010, Honolulu, Hawaii, USA pp 1178-1181.

Tao S, Guo Q, Li L, Xue B, Kelly M, Li W, Xu G, Su Y (2014). Airborne Lidar-derived volume metrics for aboveground biomass estimation: A comparative assessment for conifer stands. Agriculture and Forest Management 198-199:24-32.

Vaughn NR, Moskal LM, Turnblom EC (2012). Tree Species Detection Accuracies Using Discrete Point Lidar and Airborne Waveform Lidar. RemoteSensing 4:377-403.

Vopěnka P, Černý M (2006). GIS aided Statistical Forest Inventory in Transcarpathia, Ukraine. ArcNews 27(4).

Weir D (2012). Assessment of Processing Different Types of Vegetative Data usingLidar. Thesis report, University of New South Wales.

Yao W, Krull J, Krzystek P, Heurich M (2014). Sensitivity Analysis of 3D Individual Tree Detection from LiDAR Point Clouds of Temperate Forests. Forests 5:1122-1142.

Zhao K, Popescu SC, Nelson R (2009). Lidar remote sensing of forest biomass: A scale-invariant estimation approach using airborne lasers. RemoteSensing ofEnvironment 113:182-196. 